\title{
CONFISSÕES DE UM HETEROSSEXUAL ASSUMIDO: PARADOXOS DA HETERONORMATIVIDADE NA AUTOESCRITURA DE WILLIAM BUTLER YEATS
}

Raimundo Sousa (UFMG)

Adelaine Laguardia (UFSJ)

Resumo: O gênero se constitui iterativamente sob efeito de performances conformativas ou disruptivas em relação à heteronormatividade, pois a mesma cadeia de repetição que o naturaliza pode operar inversamente, revelando seu caráter contingente e imitativo. As autoescrituras, práticas textuais de autorepresentação, fornecem indícios de como se dá a constituição performativa do gênero, na medida em que o autor, ao se construir biograficamente, constrói-se como um sujeito generizado. Sob tais premissas, investigamos, a partir de registros autoescriturários de W. B. Yeats, seu empenho em se adequar às diretrizes da heteronormatividade e a forma como esse esforço se torna contraproducente na medida em que o escritor desmantela oposições binárias supostamente estáveis entre masculinidade e feminilidade, hetero e homossexualidade, pelo trânsito entre pólos que a cultura pressupõe como ontologicamente opostos. Noutros termos, apesar de sua obstinação por estabilidade identitária, Yeats desconstrói a noção mesma de identidade e, não obstante seu esforço em ratificar sua heterossexualidade, acaba por desorientar a orientação sexual.

Palavras-chave: W. B. Yeats, Autoescritura, Heteronormatividade, Paradoxos.

Abstract: Gender is constituted iteratively under the effect of conformative or disruptive performances in relation to heteronormativity, since the same chain of repetition that naturalizes it can operate inversely, revealing its contingent, imitative character. Self-writings, or textual practices of self-representation, provide clues about the ways in which performative constitution of gender occurs, in that the author, when constructing himself biographically, does it as 
a gendered subject. Under these assumptions, we investigate, through self-writing registers by $\mathrm{W}$. B. Yeats, his commitment to fit the guidelines of heteronormativity and how this effort becomes counterproductive as the writer dismantles supposedly stable binary oppositions between masculinity and femininity, hetero and homosexuality, by the traffic between poles that culture presupposes as ontologically opposed. In other words, despite Yeats's obstinacy for identity stability, he deconstructs the very notion of identity and, despite his efforts to ratify his heterosexuality, he ultimately disorientates sexual orientation.

Keywords: W. B. Yeats, Self-Writing, Heteronormativity, Paradoxes.

\section{À GUISA DE INTRODUÇÃO}

Longe de inscrito biologicamente, o gênero, sob uma lente construcionista, constitui-se pela iteratividade de performances corporais que, pelo modo como respondem às interpelações dos aparatos disciplinares, ou engendram ilusão de naturalidade, se obedientes à gramática heteronormativa, ou revelam sua contingência como construto social, se capazes de expor como a identidade é engendrada nas e pelas próprias práticas que supostamente a exprimem (BUTLER, 1990). A nosso ver, também as performances textuais, sobretudo as autoescrituras ${ }^{1}$, produzem efeito de gênero na medida em que este, enquanto marcador identitário, opera como elemento estruturante desse exercício de construção textual da identidade. Uma

1 Por autoescrituras nos referimos a práticas textuais (notadamente autobiografias, memórias, diários e cartas) notabilizadas por operarem na tênue fronteira entre a factualidade e a ficção, convertendo possíveis fatos em artefatos, e construírem uma auto-representação do autor-personagem, que, inscrito simultaneamente como sujeito e objeto do discurso, forja uma imagem-de-si mediante convenções enunciativas como a escrita em primeira pessoa. 
vez que definir-se implica, em última instância, narrar-se, as autoescrituras, ao conferirem concretude à abstrata noção de identidade, permitem perscrutar como o autorpersonagem, ao se construir textualmente, constrói-se como um sujeito generizado, e, enquanto práticas sociais, informam acerca tanto da persona(lidade) enunciativa como do regime de representação em que esta se inscreve.

Numa contemporaneidade sob o signo da pseudoliberação sexual, esse liame entre autotextualização e performatividade de gênero é catalisado por um mercado editorial inflacionado pela profusão de autoescrituras assinadas por homossexuais e transgêneros. Atenta à rentabilidade mercadológica da cultura queer, a indústria cultural tem-se empenhado em deslocar homossexuais do closet para as prateleiras, onde, encadernados em (auto)biografias, são inscritos/escritos como sucedâneos dos santos medievais numa cultura pósmoderna balizada pela perda de referenciais e, portanto, carente de heróis para consumo ${ }^{2}$. Se na hagiografia a coragem do asceta em assumir sua orientação religiosa o alçava como exemplum a ser emulado pelos cristãos, em sua congênere secular a galhardia do homossexual em assumir sua orientação sexual o edifica como modelo para identificação

2 É significativo que Oscar Wilde e Michel Foucault, dois ícones adotados pela cultura queer, sejam referenciados como santos em publicações como Saint Oscar (EAGLETON, 1989) e Saint Foucault (HALPERIN, 1995). 
introjetiva por aqueles ainda "no armário". Paralelamente a esse fenômeno - cujo contributo para o desmantelamento da heteronormatividade pela politização de sexualidades dissidentes coexiste com o risco de cooptação pela lógica do espetáculo e consequente obsolescência -, pesquisadores foucaultianos revisitam o último quartel do século XIX, quando da invenção do homossexual como categoria taxonômica, a fim de traçar perfis biográficos dos "pais" simbólicos da homossexualidade, como Oscar Wilde, investigando como o biografado se assume homossexual em negociação com códigos culturais heterocêntricos.

Sem o intento de valorar o agenciamento resultante do coming out, interessa-nos sublinhar que, dentre outras possibilidades semânticas, o verbo assumir comporta três significações distintas - quais sejam, "apropriar-se (de)" (e.g. assumir um cargo), "exibir" (e.g. assumir uma pose) e "revelar(-se)" (e.g. assumir uma orientação sexual) -, das quais a última tem sido investida politicamente na agenda LGBTTTs como quesito para heroicização. Precisamente porque tal verbo se cristalizou numa acepção confessional cristianizada, em princípio nao teria por que investigar, por exemplo, como um heterossexual se assume, uma vez que sua orientação sexual jamais precisou ser 
mantida em segredo. Todavia, considerando-se a ruptura epistemológica implicada no deslocamento conceitual do gênero, ressemantizado de dado biológico para construto social, não problematizar a heterossexualidade implica concebê-la como um fluxo natural, distinto da homossexualidade, que, como exceção, seguiria um curso mais sinuoso e problemático. Dada a inscrição daquela como norma(lidade) por razões historicamente determinadas, o assumir-se heterossexual não tem sentido na acepção de revelação (de subjetividades recalcadas), mas, se tomado como apropriação e exibição (de paradigmas naturalizados), enseja um exercício desconstrutivista ao expor a identidade de gênero como não mais do que a tomada de posições-de-sujeito legisladas pelos discursos dominantes e evidenciar, portanto, que não há orientação sexual prédiscursiva. Ora, uma vez que, interpelados continuamente a exibirmos performances preestabelecidas que reiterem nossa alocação em determinada identidade, constituímonos em certa medida imitativamente, toda (con)formação identitária configura, a rigor, uma modalidade de camp; daí o aforismo de RuPaul (1995): "você nasce nu; tudo o mais é drag" (p.iii; nossa tradução³).

Uma forma atrevida de problematizar a heterossexualidade

3 Todas as traduções de citações em língua estrangeira foram feitas por nós. 
como efeito performativo no qual a estrutura imitativa e contingente do gênero também se revela consiste em investigar seu processo de (con)formação tomando como conceito operatório o próprio verbo "assumir", convencionalmente atrelado ao universo gay/lésbico, e evidenciar como também a heterossexualidade resulta de uma identificação sempre processual, inconclusa e suscetível às contradições constitutivas dos processos de generização. A fim de exemplificar essa proposta de deslocamento conceitual, empreendemos uma narratologia da autogenerização do anglo-irlandês W. B. Yeats em um conjunto de registros autoescriturários, atentando para os desafios enfrentados pelo escritor na tentativa de assumir a heterossexualidade e apontando como os conflitos de gênero que tiveram lugar nesse processo informaram sua criação literária. Ao trazermos a lume as contradições encerradas na busca de Yeats pela heteronormatividade, expomos uma faceta desse escritor que tem sido pouco explorada pela crítica literária tradicional e certamente ainda é desconhecida pela maioria dos leitores; afinal, se o bardo, tal como consta nos compêndios de literatura, percorreu o itinerário de um "típico" heterossexual, flertando com diversas mulheres, apaixonando-se por algumas e, finalmente, casando-se com uma delas, quais problemas de gênero poderiam tê-lo atribulado? 


\section{ENTRE A HOMOFILIA E A HOMOFOBIA}

Na episteme em que Yeats se situava, a formatação dos códigos de gênero dominantes obedecia a uma distinção conceitual entre os termos masculinidade (masculinity) e hombridade (manliness ou manhood) na qual o primeiro designava a condição biológica comum a todos os indivíduos do sexo masculino e tinha como antítese ontológica a feminilidade, enquanto o segundo designava a excelência no cumprimento dessa condição e tinha como antítese a efeminação (cf. BEDERMAN, 1996). Dessa distinção qualitativa em que a hombridade, investida de dimensão moral, transcendia a masculinidade sem deixar, contudo, de Ihe ser inerente, decorria que, embora todos os homens possuíssem esta última, nem todos atingiam a primeira, mas poderiam fazê-lo a qualquer tempo em que cumprissem os requisitos que a distinguiam.

Em sua identidade cultural hifenizada, o escritor angloirlandês era duplamente interpelado pelo paradigma de hombridade metropolitano, epitomizado pelo colonizador comprometido com o projeto expansionista inglês, e pelo paradigma contrapontual irlandês, metonimizado pelo rebelde nacionalista engajado na luta pela descolonização. Mais do que o dilema entre códigos de gênero concorrentes, 
a inaptidão para um e outro o atribulou desde a infância, quando seu prospecto de se tornar um combatente foi comprometido por sua debilidade física, pois, como "era delicado e não tinha músculos", "possuía uma péssima reputação como lutador" (YEATS, $1915^{4}$, p. 34; 40). Ainda que as pressões sociais pela adequação de gênero fossem potencializadas no clã familiar, sobretudo pelo pai, instância superegóica que o "aterrorizava" e o "humilhava" por não responder às suas expectativas $(R C Y, \mathrm{p} .33)$, a literatura e suas dinâmicas de influência lhe permitiram sobrepor a paternidade ideológica (ou o vínculo coalizivo da afiliação) à paternidade biológica (ou o vínculo consanguíneo da filiação) e se insurgir contra o pátrio poder ao adotar Rossetti, Shelley e Blake como pais simbólicos. Desvencilhandose do autoritarismo fascistóide de seu pai, que admirava homens fortes e almejava transformá-lo em um deles, Yeats se libertaria da racionalidade tecno-científica pela contraidentificação com ideologias antirracionalistas como o ocultismo e o romantismo, inserindo-se numa patrilinearidade anacrônica que lhe permitia definir-se como "[u]m romântico quando o romantismo estava em sua extravagância final" (YEATS, 1936, p. 52) e finalmente celebrar, em triunfalismo de ressonâncias edípicas, que

4 Doravante o texto será referenciado pela abreviação $R C Y$ seguida do número da página. 
"consegui romper com a influência de meu pai" (RCY, p. 102).

Afeito à efervescente homocultura vitoriana, Yeats, quando criança, admirava um professor de Grego enamorado por um garotinho "com rosto de menina" ( $R C Y$, p. 45); na adolescência, aprendeu os meandros da sexualidade com um homossexual passivo; já na juventude, seu círculo de convivialidade incluía desde homossexuais "enrustidos", como Edward Martyn e Lionel Johnson, a extravagantes, como Joseph Quinn e Oscar Wilde. Durante o processo judicial contra este último, deu-lhe apoio e, mesmo sem escapar ao heterossexismo, lembrou o conhecimento histórico como atenuante do impacto moral de "sua forma de vício" (YEATS, $1972^{5}$, p. 79). Quando, mais tarde, discutia-se a sexualidade de Roger Casement, foi assertivo ao ponderar que "[s]e Casement fosse um homo-sexual, o que importaria?" (YEATS, 1940, p. 128). Também admirador de Aubrey Beadsley, indignou-se com sua demissão do The yellow book por haver ilustrado uma peça de Wilde e argumentou que o desenhista "não tinha nenhuma anormalidade sexual" (YEATS, 1922, p. 198). Mais: um de seus primeiros mentores foi o escritor e ensaísta Walter Pater, cujo esteticismo homoerótico inspirou a homocultura finissecular e cujo romance Marius the Epicurean, Yeats considerou a única grande prosa

5 Doravante o texto será referenciado pela abreviação MEM seguida do número da página. 
do inglês moderno (1922). Mais ainda: algumas de suas primeiras criações literárias competiram para o mosaico de homotextualidades no painel literário do fin de siècle, tais como o romance inacabado The Speckled Bird, no qual dois homens mantêm entre si um grau de intimidade "possível apenas a amantes e místicos" (YEATS, 1976, p. 60).

No entanto, a masculinidade contra-hegemônica era incapaz de mitigar seus conflitos de gênero não somente por seguir o contrafluxo da militarização da cultura no préGuerra, quando se atrelava a masculinidade ao militarismo em detrimento das artes, mas, fundamentalmente, pelo efeito dos aparatos disciplinares sobre sua subjetividade. Graças à voga científica, que em fins do Oitocentos engendrou um circuito de produção e circulação de tratados médicos e antropológicos sem precedentes, sua homofilia era contrapesada por um excessivo temor quanto à degeneração, fomentado pela leitura de expoentes tanto da biologia humana (como Darwin, Huxley e Haeckel) quanto da sexologia (como Nordal, Ellis e Forel). Atravessado pelos discursos médico e racial, Yeats repetidas vezes mencionava sua suscetibilidade à exaustão nervosa e, em tom lamarckista, chegava a creditá-la à transmissão hereditária dos caracteres da mãe depressiva: "Começo a me perguntar se tenho e se 
sempre tive alguma debilitação nervosa herdada de minha mãe", escrevia em janeiro de 1909, após notar sua "própria forma de excitabilidade" na irmã Lolly, às voltas com "acessos de prolongada melancolia" (MEM, p. 156-157). Sob a égide da teoria eugenista, da qual se tornaria adepto, o escritor identificava no cruzamento disgênico de seus progenitores a predominância dos genes da mãe e, por conseguinte, a inevitabilidade de uma progênie degenerada.

Em torno da crença nessa disposição degenerativa hereditária, Yeats desenvolveu uma insegurança quase neuroide quanto ao seu estado geral de saúde e, especificamente, quanto à sua identidade de gênero, sobretudo após a descoberta da sexualidade. A partir de meados do Oitocentos, a Igreja Católica estabeleceu na Irlanda uma austera moralidade sob cujo impacto o ocultamento de informações sexuais era tal que o escritor Sean O'Faolain (1965) confessou ter chegado aos vinte anos sem saber de onde vinham os bebês e Yeats teria igual sorte não fosse o voluntarismo de um garoto que lhe explicou "todo o mecanismo do sexo" ( $R C Y$, p. 26), provocando-Ihe tamanho desconcerto que teve de consultar uma enciclopédia para crer no que ouvira. Sua estupefação se deveu menos ao conhecimento sexual do que à ambiência homoerótica 
em que este se deu, pois o jovem que o esclareceu "havia aprendido tudo sobre ele [o sexo] com um garoto mais velho, de quem era passivo, [...] e sua descrição [...], como se estivesse contando sobre um fato qualquer da vida física, deixou-me mal durante semanas" ( $R C Y$, p. 27). A cadeia estabelecida entre o rapaz instruído por outro que, por sua vez, fora ensinado por um terceiro forma um continuum sintomático do modo como, em um arranjo social balizado pela cisão de esferas de gênero, os meninos por vezes se (re)conhecem na intersubjetividade e intercorporeidade com seus pares mediante ritos homossociais (quando não homoeróticos) de transmissão de conteúdo cognitivo (quando não seminal) que franqueiam sua inserção no universo masculino.

$\mathrm{Na}$ Irlanda vitoriana e edwardiana, o atrelamento entre virilidade e castidade implicou um tour de force contra injunções venéreas animado pela consolidação da scientia sexualis como corolário da produção de saberes constituídos na e pela intersecção entre discursos e tecnologias disciplinares implementados, sobretudo, a partir da emergência de normatizações demográficas tocantes à higiene e saúde públicas. Para tanto, foram providenciais a conjunção temporal e a confluência ideológica de práticas reguladoras em princípio desarticuladas, como a 
perseguição eclesiástica ao sexo recreativo (corpo इ pecado), o dispositivo de controle subliminar ao elogio do trabalho pelo modo de produção capitalista (corpo $\equiv$ máquina) e a criação de taxonomias sexuais e raciais, respectivamente, pelos discursos médico (corpo $\equiv$ corpus) e raci(ali)sta (corpo 三 signo de diferença racial). Imerso nessa formação discursiva que condenava a sexualidade descomprometida com a reprodução racial, Yeats experienciou seu primeiro orgasmo de modo igualmente traumático, porque assentado em autodidatismo também heteróclito às diretrizes da masculinidade heteroreprodutiva. Em seu primeiro volume autobiográfico, o escritor registra a descoberta do autoerotismo em tom impessoal, universalizando suas sensações corpóreas pela referência em terceira pessoa:

O grande evento da vida de um menino é o despertar do sexo. Ele tomará banho diversas vezes ao dia, ou se levantará ao amanhecer e, tendo-se despido, pulará de um lado para outro [...] e mal saberá, e jamais admitirá, que havia começado a sentir prazer em sua própria nudez. (RCY, p. 70)

Essa ode ao narcisismo, na qual o prazer autoerótico constitui um entretenimento solitário desprendido de culpa, prova-se inverossímil quando contraposta pelos primeiros rascunhos do mesmo texto, publicados postumamente, 
nos quais Yeats assume um tom confessional tipicamente rousseauniano em depoimento mais revelador acerca da natureza e implicações da autogratificação genital:

Eu era torturado pelo desejo sexual e vinha sendo há muitos anos. [...] Eu havia me banhado, me deitado ao sol [...] e coberto meu corpo com areia. Logo o peso da areia começou a afetar o órgão do sexo, embora, a princípio, eu não soubesse o que era aquela sensação estranha e crescente. Fui descobrir somente com o orgasmo [...]. Dali adiante foi uma luta contínua contra uma experiência que quase invariavelmente me deixava com os nervos exaustos. 0 sexo normal não me afeta mais do que aos outros homens, mas esse [...] era uma plena ruína. Deixava-me com repulsa por mim mesmo. (MEM, p. 71-72)

Nesta primeira versão, despojada de censura, mas impregnada de constrangimento flagrante no uso de eufemismos, o autor lembra um confidente que, em tom contrito, revela os pormenores de sua ilicitude, porém não à maneira agostiniana: embora na Irlanda a ciência, na contramão da ordem global, não ameaçasse a pastoral pedagógica monopolizada pela Igreja, Yeats, como cristão dissidente, referia-se à masturbação não como pecado, mas como patologia, de sorte que o foco de seu temor era a degradação antes orgânica que anímica. 
Sua auto-abjeção evidencia a eficácia dos dispositivos de controle atingida pela internalização da norma pelo sujeito, que se torna censor de si mesmo ao introjetar uma concepção de sexualidade, fincada na dicotomia normal/patológico, na qual a masturbação configura um mal absoluto. Ao creditar sua exaustão nervosa aos hábitos masturbatórios, o memorialista reproduz pre(con) ceitos do discurso médico contemporâneo, para o qual o sêmen, enquanto fluido vital, deveria ser gasto com o propósito único da procriação, dado que seu dispêndio excessivo seria danoso a todo o organismo. Ainda segundo o discurso médico, o "auto-abuso", ao demandar intenso esforço mental, não só arruinaria o sistema nervoso como redundaria em esgotamento generalizado, e o onanista, física e moralmente débil devido ao abandono à impudicícia, tornava-se efeminado e perigava, inclusive, transformarse em homossexual - já que a medicina pressupunha uma relação cumulativa na qual um vício desencadeava outro, de forma que o onanista era um homossexual em potência (MOSSE, 1985).

Inseguro quanto à sua reputação de gênero sob impacto dos discursos médico e racial, Yeats, ao rememorar sua crise nervosa ocorrida no verão de 1897, mencionava brevemente, 
em seu terceiro volume autobiográfico, que sua frustração amorosa era tal que seus nervos "tinham sido destruídos" (YEATS, 1936, p. 19). Novamente, a narrativa suplementar traz a lume as rasuras da versão oficial, já que, livre das pressões que circunscrevem os limites do narrável, aqui o escritor atribui sua crise nervosa à prolongada abstinência sexual e à masturbação como malsucedida tentativa de alento:

Foi uma época de grande tensão pessoal e tristeza. Desde que minha amante [Olivia Shakespear] me deixara, nenhuma outra mulher havia entrado em minha vida e, por quase sete anos, nenhuma entrou. Eu era torturado por desejo sexual e desapontamento amoroso. [...] Quando o desejo se tornava uma tortura insuportável eu me masturbava, e isso, não importa quão moderado eu era, me fazia mal. (MEM, p. 125)

O abandono por Olivia Shakespear, que o iniciara sexualmente quando este já contava trinta anos, e a consequente revivescência de sua antiga obsessão por Maude Gonne catalisavam um círculo vicioso em que a ansiedade sexual o conduzia à masturbação, que, por sua vez, engendrava mais ansiedade. Se bem que reconhecesse o onanismo como corolário de sua condição celibatária, e não como um vício, Yeats aqui também é assaltado pela culpa e autopunição, afinal, em um contexto de apogeu do 
nacionalismo, que valorava a masculinidade em termos de salubridade psicofísica e correção moral, identificava como fraqueza sua autoindulgência.

Epítome de sua introspecção e insulamento aristocrático, o "sexo solitário" estigmatizaria o poeta, pois, ainda que não o praticasse regularmente, sua reputação como masturbador inveterado o tornava alvo de chacota em um país no qual o estereótipo do onanista egocêntrico, solitário e dado a excessos contradizia um projeto de nação que atrelava a hombridade a valores como altruísmo, coletivismo e autocontrole. Em 1905, por exemplo, o médico Oliver Gogarty o difamou, em versos rimados, como sexualmente imaturo e impotente por haver declinado a investidura amorosa de sua admiradora Annie Horniman:

What a pity it is that Miss Horniman / When she wants to secure or suborn a man / Should choose Willie Yeats / Who still masturbates / And at any rate isn't a horny man. (Apud FOSTER, 1998, p. 330)

O heteropatriarcado, que em princípio favoreceria incondicionalmente os homens, revela-se mutilador para aqueles à margem do padrão de masculinidade hegemônico, já que enquanto um homem que mantém várias mulheres é ovacionado como sedutor, aquele que rejeita uma delas tem sua hombridade posta em cheque. Yeats sofreu os efeitos 
dessa dualidade em um sistema de valores que interpretava como emasculação sua recusa a mulheres como Horniman e sua continência quase permanente até os 51 anos, quando finalmente se casou. Incompreendida pelos contemporâneos, sua rejeição a mulheres de fácil conquista e sua obsessão por outras de difícil acesso guarda relações com seu ideal estético, que, assentado nos protocolos do amour courtois, pressupunha que o mérito feminino consistia em representar um enigma para o homem e, assim, instigar suas faculdades imaginativas, servindo-lhe de inspiração nas Letras e Artes. Essa crença, como se verá a seguir, impeliu Yeats na busca pela heteronormatividade.

\section{ENTRE O SUPER-HOMEM E A PRINCESA}

Ambivalente quanto à autogratificação genital, Rousseau a concebe, em Les confessions, como um "perigoso suplemento" que "protege os jovens [...] de desordens várias, à custa de sua saúde, de seu vigor e, por vezes, de sua vida" (1782, p. 249). Ao apontá-la, ainda, como "grande atrativo para imaginações vívidas" (1782, p. 249), o filósofo nos impele à analogia entre a masturbação e a composição literária, já que uma e outra dependem da faculdade imaginativa; e entre o onanista e o escritor, pois ambos, em labor solitário, criam personagens e enredos. Em contraposição, Yeats vincula o onanismo 
exatamente ao tolhimento da capacidade criativa por agravar sua disfunção nervosa, impedindo-Ihe de escrever, e considera que o pleno exercício de sua habilidade cognitiva depende de sua orientação para a heterossexualidade: "Eu acreditava", lembra o escritor, "que uma vez conquistado [...] a inclinação da minha mente para as mulheres e o amor eu viveria [...] em busca do saber" (RCY, p. 81). A dupla mirada por orientação estética e sexual seria, portanto, a mola propulsora de sua carreira, de modo que, a seu ver, quanto maior sua aproximação do paradigma de masculinidade heteronormativa, tanto maior seu êxito literário.

Entretanto, numa formação discursiva que codificava a homossexualidade como uma "inversão" na qual a mente operaria conforme a do sexo oposto - donde a conhecida formulação anima muliebris virili corpore inclusa -, alguns de seus predicados mais notórios, como a introspecção, a emotividade, o preciosismo linguístico e o uso de eu lírico feminino eram tomados como índices de efeminação e utilizados como trunfo por seus desafetos políticos e intelectuais. Dentre vários outros, Frank Hugh O’Donnell (1899) o acusou de representar os irlandeses como inviris, Francis Shaw (1934) o denunciou por converter heróis nativos em efeminados sonhadores e Frank Fay o criticou 
por trazer à Irlanda uma "arte efeminada", ponderando que em vez de "belas palavras \& sons" o país carecia de "pensamento masculino" (Apud SCHUCHARD, 2008, p. 241). Na qualidade de expoente do projeto nacional irlandês, Yeats deveria metonimizar a virilidade céltica, em contraponto à feminização da raça pelo discurso colonial, mas suas características femininas o corroboravam. ${ }^{6}$ Daí o empenho de seus defensores em representá-lo de forma hercúlea, como fez o ensaísta Robert Lynd ao contestar sua caracterização como "uma pessoa efeminada e sonhadora" para descrevêlo, ao revés, como "um homem de energia aquilina" e "um incansável lutador por suas ideias" (1919, p. 176).

Sua reputação como efeminado motivaria alterações contundentes em seu estilo literário ao final do Oitocentos, quando em voga a tese apocalíptica, propalada sobretudo por Nordau (1895), de que a cultura finissecular perdia sua virilidade em processo de franca degeneração. Principal difusor desse conceito no âmbito da crítica social, o médico húngaro identificava como degenerados não apenas tipos sociais convencionais como também grupos intelectuais

\footnotetext{
6 O império encontrou na feminização da colônia um expediente determinante para assegurar sua autoridade, inscrevendo a colonização na esfera das relações entre homem e mulher e acentuando a diferença entre celtas e anglo-saxões mediante distinções entre masculinidade e feminilidade. Se o colonialismo se pautou, grosso modo, na feminização dos colonizados, a reação a essa estratégia de desempoderamento consistiu, sobretudo, na obsessão pela masculinidade como quesito preponderante para, em nível psíquico, o resgate da auto-estima dos irlandeses, e, em nível político, a aquisição do seu autogoverno.
} 
como os Pré-Rafaelitas, os simbolistas e os místicos - e Yeats se vinculava aos três grupos - ao tomar suas criações literárias hipersexuadas, assexuadas ou hermafroditas como sintomas de mentes adoecidas por pulsões eróticas degeneradas. No entanto, em estudo sobre os limites da homofilia de Yeats, Edwards sustenta que esta foi "brevemente perturbada" em meados dos anos 1890 sob o efeito do escândalo protagonizado por Wilde e da teoria degeneracionista de Nordau, que o embaraçou quanto à sua identidade de gênero, mas que ao final do século, restabelecido desse impacto, o literato começou a "desafiar" tal teoria (1997, p. 44). Todavia, Edwards não buscou fontes bastantes para observar que, ao invés de contestar Nordau, Yeats iterou sua diagnose da cultura contemporânea como decadente, porque efeminada. No mesmo período que supostamente ter-se-ia recomposto do impacto das teorias degeneracionistas, o escritor acentuava sua obsessão por balizas de gênero em patente demonstração de insegurança identitária. Dado que o falogocentrismo se organiza em torno de dualidades que, em última análise, assentam-se na dicotomia matricial masculino/feminino, naquela conjuntura de instabilidade das fronteiras de gênero e tentativa de se manter um cordon sanitaire entre masculinidade e feminilidade se generizava quase tudo, inclusive as artes. 
Inscrito nesse sistema de representação diádico e aderindo ao findesieclisme não apenas por afinidade estética como, principalmente, por ansiedade de gênero, Yeats se valia de estereótipos generizados para denunciar a degeneração da literatura no fin de siècle, sobretudo a poesia, definindo-a como "efeminada" devido ao seu "desgastado lirismo" (YEATS, 1962, p. 220), e enaltecer John Synge como aquele que "trouxe de volta a hombridade ao verso irlandês com sua rude desilusão" (YEATS, 1936b, p. xiii).

Impactado por uma formação discursiva que patologizava a figura do esteta como efeminada, Yeats experienciava uma crise pessoal que o levaria a reavaliar sua (est)ética. Metonimizando um projeto nacional fincado na busca pela remasculinização em contraponto à sua feminização pelo discurso colonial, o escritor passa a almejar valores másculos, identificando-se com "os escritores masculinos" (YEATS, 1962, p. 221), e, para tanto, abandona seus pais simbólicos, substituindo-os por outros. Se nos anos 1880 enaltecia os Pré-Rafaelitas, agora os renega em prol de William Blake, considerando-o o mais enérgico dos românticos. Se, também naquela década, cultuava o esteticismo de Walter Pater, agora refuta o crítico literário, desdenhando que seu ideal de cultura "só é capaz de formar 
almas femininas" (MEM, p. 159), e, em contraposição, encanta-se por Nietzsche e almeja seu ideal de virilidade sintetizado na noção de Super-Homem (Übermensch). Mesmo tendo na poesia seu grande mérito literário, voltase temporariamente para o drama por caracterizá-lo como "a busca por energia mais masculina" (YEATS, 1906, p. xii) e tenta expurgar de sua escrita tudo quanto fosse índice de efeminação, reescrevendo algumas peças com vistas à “adição do elemento masculino" (YEATS, 1962, p. 220). Todavia, essa crítica à literatura contemporânea não passa de uma forma projetiva de autocrítica, como evidencia seu mea culpa por não conseguir expressar devidamente seu ódio pela experiência colonial: "Eu me acuso de efeminação por não tê-lo dado expressão adequada" (YEATS, 1968, p. 519). A autopunição também é perceptível na carta de 1904 a George Russell, na qual o missivista renega sua produção poética inicial como "inviril", condenando sua "subjetividade", "decadência", "fraqueza", "exagero de sentimento" e "introspecção mulheril" (YEATS, 1954, p. 434).

Curiosamente, ao traçar um perfil biográfico de Yeats, atendo-se ao seu período de formação, Mutran conclui que até 1901 o escritor tivera uma vida "maravilhosamente plena" (2002, p. 214). Tal conclusão só é possível quando se 
passa ao largo dos conflitos de gênero que o atribularam no período recortado pela pesquisadora, que, ao desvincular sua carreira de sua crise de gênero, sugere que esta, relegada à esfera íntima, não reverbera em sua estética. Ao sustentar, ainda, que o convívio com os decadentistas não afetou seu "temperamento", pois Yeats "ia descartando aquelas [ideias] que não Ihe pertenciam" (2002, p. 197), Mutran pressupõe que o poeta estava "pronto" e, por isso, rejeitava ideias exteriores, quando, ao contrário, tentava exorcizar de si mesmo tudo quanto havia assimilado e agora comprometia seu intento de assumir uma identidade heteronormativa. Ora, as vicissitudes de sua carreira não se devem à mera alteração de gosto pessoal ou amadurecimento intelectual, pois, quando consideramos os conflitos de gênero subjacentes a elas, verificamos que estes constituem a chave mestra para a compreensão de sua literatura no que tange às rupturas de estilo e afiliação estética.

O empenho de Yeats pela adequação aos protocolos da masculinidade heteronormativa não se deu, contudo, sem paradoxos. É revelador que, na mesma correspondência a Russell, o poeta reconheça a dificuldade em se desvencilhar da feminilidade que o atrai e o domina: "Como sempre acontece com algo por que se tem sido tentado e por que 
ainda o é um pouco, estou despertado por ela a uma espécie de ódio frenético completamente fora do meu controle" (YEATS, 1954, p. 434). Também elucidativos são o poema "Coole Park", no qual o bardo se autorreferencia como "aquele que se desconcertava numa pose viril / Por todo o seu tímido coração" (YEATS, 1956, p. 96), e, sobretudo, a carta de 1936 à escritora lésbica Dorothy Wellesley, na qual o remetente, endossando a perspectiva junguiana de que homens e mulheres possuem um quantum do sexo oposto em sua composição psíquica, reconhece sua faceta feminina ao declarar que "quando você atravessou a sala com aquele movimento de garoto não era um homem que olhava para você, era a mulher em mim" (YEATS, 1940, p. 108).

Seu sentimentalismo romântico e sua adesão ao ocultismo, doutrina impregnada de valores "femininos", dificultavam sua busca por virilidade, resultando que mesmo seus vínculos heterossexuais fugiam à heteronormatividade. Embora seu ideal estético dependesse da passividade da mulher como símbolo e inspiração para o exercício de sua faculdade criativa, o poeta admirava mulheres fálicas, possuidoras do animus de que ressentia como contrapeso de sua anima, tais como Florence Farr, Eva Gore-Booth, Constance Markievicz, Laura Armstrong e Maud Gonne. Também sua passividade em 
relação às mulheres, notadamente as "musas" Armstrong e Gonne, contradiziam o ideal racionalista de um self masculino autônomo e centrado que credenciava ao homem o papel de a(u)tor da História. Se bem que o conceito de musa, formulado numa matriz androcêntrica, tenha conotação estritamente simbólica, ambas não eram de modo algum passivas, pois ora o impeliam a agir e ora agiam junto com ou por ele. Enquanto no enredo esquemático dos contos de fadas o príncipe desperta a princesa do sono letárgico - gesto que em interpretação psicanalítica simboliza a passagem feminina do estado de latência para a maturidade sexual e, portanto, para a aptidão procriativa (BETTELHEIM, 1976) -, Yeats reconhecia que a primeira "despertou-me do sono metálico da ciência e me pôs a escrever minha primeira peça" (YEATS, 1953, p. 90), isto é, facultou-lhe a passagem da improdutividade para a fertilidade criativa.

Ainda mais emblemática é sua relação com a segunda, na qual se invertem binarismos de gênero. Ativa, objetiva e defensora do nacionalismo radical, Gonne contrastava com um Yeats contemplativo, subjetivo e afeito ao nacionalismo moderado. Contrariando o axioma de que os opostos se atraem, a musa declinou suas diversas propostas de matrimônio, justificando ter repulsa pelo sexo, embora 
tivesse sido amante de um soldado e jornalista francês e viesse a se casar com John MacBride, que lutara na Guerra dos Bôeres e seria um dos líderes do Levante da Páscoa. Inapto ao perfil de masculinidade beligerante que a fascinava, Yeats teve de se contentar com um "casamento místico" no qual, segundo Gonne, "[n]ossos filhos eram seus poemas, dos quais eu era o pai semeando a inquietude \& a tempestade que os tornaram possíveis \& você a mãe que os pariu em sofrimento" (YEATS; GONNE, 1994, p. 37). Contudo, essa inversão de gênero em nível simbólico escamoteia a manutenção de assimetrias em nível material, pois, mesmo ciente de sua atuação ativa no processo criativo e do papel passivo de Yeats como receptáculo da inseminação, Gonne lhe atribui toda a autoria dos poemas, instaurando um paradoxo cujas raízes se fundam no androcentrismo ocidental. Segundo Gilbert e Gubar (1979), a hegemonia masculina nas Letras se sedimentou em metáforas de paternidade literária, de maneira que "o autor do texto é um pai, um progenitor [...] cuja pena é um instrumento de potência geradora tal como seu pênis" (p. 6). Diversamente do que argumentam as autoras, essa hegemonia é codificada, antes, em metáforas maternas, já que no imaginário ocidental a noção de parto como sofrimento, que remonta ao castigo imposto à mulher primordial, coaduna-se com a acepção 
de escrita como esforço penoso e fruto de desgastante processo de gestação, resultando que a criação intelectual é frequentemente comparada à progenitura - veja-se o termo maiêutica (parturição), utilizado por Sócrates, filho de parteira, para designar o "parto" das ideias. Iterando essa fantasia uterina que atribui ao homem o poder de dar à luz, o próprio Yeats equacionava o trabalho criativo ao trabalho de parto, afirmando que "[o] homem é uma mulher para seu trabalho, e ele [o trabalho] pare seu pensamento" (MEM, p. 232). Se, como denuncia o feminismo marxista, a tarefa da reprodução/procriação segrega a mulher da esfera da produção/criação, tomar metaforicamente este último domínio, monopólio masculino, pelo primeiro sugere uma falsa conciliação entre dois epicentros cindidos pela cultura.

\section{DO PÊNIS FLÁCIDO À SEGUNDA PUBERDADE}

A ansiedade de gênero que atormentou Yeats por toda a vida culminaria, já na velhice, com uma última faceta que também teria implicações em sua literatura. Para o saber médico à sua época, a masturbação, para além de causar esgotamento nervoso, constituía ameaça demográfica por redundar em impotência e esterilidade. Enquanto na metrópole especialistas apontavam como seu corolário o "encolhimento do pênis", sustentando 
que, em decorrência do "vício solitário", o membro "fica murcho" e os testículos "pendem muito mais para baixo do que o natural" (PERRY; PERRY, 1847, p. 68), também os médicos irlandeses a relacionavam à impotência e mesmo à castração, como fez um cirurgião dublinense, que, ao discorrer sobre certa patologia infecciosa que atingia os testículos, levando à amputação, destacava o onanismo em sua etiologia (GUNN, 1906). Insuflado, em certa medida, pelo espectro da masturbação, o horror pela impotência sexual acompanhou Yeats, de modo latente ou manifesto, também durante toda a vida. No campo da criação literária, é sugestivo que a torre, seu principal símbolo fálico, seja evocada para metaforizar exatamente a impotência em poemas como "Blood and the Moon", que estabelece analogia entre seu design e o pênis mortificado ao indagar se "toda nação moderna [é] como a torre, / Meio morta no topo" (YEATS, 1929, p. 11). Já nos ensaios de crítica social, o literato evoca o pênis aleijado ou impotente como tropo para a esterilidade intelectual, comparando os eunucos e os ideólogos reacionários, estéreis, respectivamente, em nível anatômico e intelectual. Em defesa de Synge contra os opositores de The playboy of the Western world, por exemplo, o escritor define a intelectualidade improdutiva destes últimos como "o equivalente intelectual da remoção 
dos genitais" e desdenha que estes "contemplam toda potência criativa como os eunucos contemplam Don Juan" (YEATS, 1936a, p. 112).

Sua analogia entre (im)potência sexual e (im)potência criativa não se restringia, contudo, aos domínios da poética e da retórica, pois Yeats compreendia a libido como élan criador, chegando a considerar que "[t]odas as artes brotavam do amor sexual" (YEATS, 1976, p. 106). A aptidão para o coito seria tão preponderante em sua carreira literária que, como afirmaria um de seus biógrafos, sexo e poesia se concatenavam em sua mente de tal modo que "[n]ão ser incapaz de fazer um significava não ser capaz de fazer o outro" (ELLMANN, 1986, p. 40). Nessa transversalidade entre genre e gender reside o ponto nevrálgico também da última fase de sua carreira. Como coroamento de uma série de ironias para um homem inseguro quanto à sua hombridade, Yeats se casaria, aos 51 anos, com "George"7. O casamento, que parecia finalmente ter aliviado suas ansiedades de gênero, fazendo-o reconhecer que a esposa tornara sua vida "serena e repleta de ordem" (YEATS, 1954, p. 634), acabou suscitando outro conflito, já que, por ter-se casado quase na velhice, o escritor era agora atormentado pela insegurança quanto à virilidade no sentido de desempenho propriamente sexual. É revelador que, quando

7 Nome adotado por Georgie Hyde-Lees, com quem contraiu matrimônio em 1917. 
em voga o método pioneiro do endocrinologista vienense Eugen Steinach, notabilizado por desenvolver a vasectomia como forma de intensificar a produção de testosterona, conter o envelhecimento e restaurar a potência sexual, Yeats tenha procurado o conhecido cirurgião Norman Haire, relatandoIhe que havia perdido toda a inspiração e que desejava reaver sua potência e, por conseguinte, sua criatividade (ELLMANN, 1986). Em 1934, contando 68 anos (e sua esposa 42), o escritor se submeteu à cirurgia e, embora seu efeito clínico fosse contestável, sentiu que o duplo revigoramento de sua energia sexual e criativa foi tal que se referiu a seus últimos anos como uma "segunda puberdade" (ELLMANN, 1986, p. 40). Embevecido, o poeta, que precisou se tornar literalmente estéril para se manter simbolicamente fértil, tratou logo de participar aos amigos seu rejuvenescimento e, poucos meses após a operação, escrevia a Virginia Woolf que: "finalmente recuperei minha potência" (cf. WOOLF, 1979, p. 341); já em 1936, revelava a Olivia Shakespear: "Estou escrevendo mais e melhor do que vinha fazendo há anos" (YEATS, 1954, p. 860).

Ainda assim, Yeats não obedeceu a contento as injunções da masculinidade hegemônica, tornando-se novamente alvo de gracejos nos círculos sociais dublinenses. Uma vez que Steinach supostamente implantava glandes de macacos em 
seus pacientes, o literato passou a ser conhecido, após a cirurgia, pelo trocadilho "Glande Velho" (SQUIER, 2004, p. 300) e, mais ainda, a ser acusado de hiperestesia sexual. 0 mesmo Oliver Gogarty que o rotulara como impotente desta vez o ridicularizava exatamente pela incontinência ao afirmar que, após a operação, "[o] pobre tolo e velhota [...] anda agora enredado e envolvido pelo sexo" (Apud FOSTER, 2005, p. 499). Mais uma vez, Yeats era vítima da contingência da masculinidade enquanto construto delimitado por injunções históricas e, por conseguinte, passível de diferentes critérios de valoração: se a priori da intervenção cirúrgica a impotência punha em cheque sua hombridade, agora a excessiva concupiscência, prova de fraqueza moral e, portanto, de efeminação, distanciava-o do autocontrole, outro quesito preponderante para a hombridade.

\section{À GUISA DE CONCLUSÃO}

Ao leitor que, interessado tão-somente na fatura da composição textual, indagaria qual o vínculo possível entre gênero, sexualidade e poiesis, demonstramos como gênero e sexualidade, longe de circunscritos ao foro íntimo, estão imbricados, como artefatos culturais, também na dinâmica da criação literária e como na carreira de Yeats a oscilação entre fases "masculinas" e "femininas" obedece menos a 
convenções estéticas do que aos conflitos de gênero sob cuja base se fundam suas concepções poéticas.

Ainda que Yeats procurasse se orientar conforme os ditames da heteronormatividade, seu processo de (con) formação identitária não se deu sem contradições, pois no transcurso de toda a sua vida o poeta se viu a braços com diversos paradoxos que dificultavam sua adequação aos paradigmas heteronormativos: interpelado por padrões de hombridade calcados na racionalidade e beligerância, porém afeito ao sentimentalismo e pacifismo; beneficiado enquanto homem branco, burguês e de origem inglesa, mas, enquanto colonizado, vítima da castração política colonial; adepto de filosofias ginófilas como o ocultismo e admirador de mulheres transgressivas, porém herdeiro de uma tradição romântica androcêntrica e simpático à noção aristocrática de ordem centrada na estratificação de gênero; identificado mais com as mulheres do que com os outros homens, adotava eu lírico feminino e se considerava mãe de seus poemas, porém se incomodava com seu caráter "efeminado" e aspirava à falicização; cultuava a passividade feminina como complementar à atividade masculina, mas sofria ação de mulheres em seu fazer poético e fora iniciado sexualmente por uma delas; repudiava a inserção feminina na esfera 
pública, porém convivia com sufragettes e não se constrangia em ser sustentado financeiramente por mulheres; aderia à psiquiatrização da sexualidade não reprodutiva, mas praticava a masturbação, simpatizava com homossexuais e foi um dos maiores defensores de Oscar Wilde.

Se concebermos a identidade não como essência, mas, antes, como aprendizado cultural, percebemos que essas contradições e ambiguidades que, à primeira vista, sugerem um self desorientado são índices de instabilidade interna das próprias categorias identitárias. Se a desconstrução consiste na desmontagem da lógica interna de categorias com vistas a expor suas contradições e limitações, Yeats desconstrói a heteronormatividade no próprio esforço de cumpri-la na medida em que desmantela oposições binárias supostamente estáveis entre masculinidade e feminilidade, hetero e homossexualidade pelo trânsito entre pólos que a cultura pressupõe como ontologicamente opostos. Assim, os paradoxos que, em leitura apressada, podem ser atribuídas a Yeats, são intrínsecos à própria noção de identidade de gênero; afinal, qualquer fixação identitária tem seu êxito comprometido não apenas pelo que exclui e a ameaça externamente como por sua inconsistência interna. 
Por isso, ainda que Yeats fosse rotulado como efeminado, reconhecesse sua efeminação e tentasse se virilizar; ainda que durante a maior parte de sua vida o sexo heteronormativo tenha sido uma experiência fortuita; ainda que sua postura passiva e masoquista no amor e na criação literária ratificasse sua "inversão" de gênero, não tecemos conjecturas acerca de sua possível homossexualidade, manifesta ou latente, pois compreendemos que não há um núcleo interno subjacente à performance de gênero (BUTLER, 1990). Em perspectiva pós-identitária, no lugar de categorizá-lo como hetero, homo ou bissexual, preferimos ressaltar como sua busca por inscrição identitária desloca a noção mesma de identidade e como suas performances subvertem a norma no ato mesmo de sua suposta iteração, de forma que, no esforço em se assumir heterossexual, Yeats acaba, em última análise, desorientando a orientação sexual.

\section{REFERÊNCIAS}

BEDERMAN, G. Manliness \& civilization: A cultural history of gender and race in the United States, 1880-1917.

BETTELHEIM, B. The Uses of Enchantment: The Meaning and Importance of Fairy Tales. New York: Random House, 1976.

BUTLER, J. Gender Trouble: Feminism and the subversion of identity. New York: Routledge, 1990.

EDWARDS, J. "The generation of the green carnation: sexual degeneration, 
the representation of male homosexuality, and the limits of Yeats's sympathy". In: STEVENS, H.; STEPHENS, C. (Eds.) Modernist Sexualities. Manchester: Manchester University Press, 2000. p. 41-55.

EAGLETON, T. Saint Oscar. Derry: Field Day, 1989.

ELLMANN, R. W. B. Yeats's second puberty. In: Four Dubliners: Wilde, Yeats, Joyce and Beckett. New York: George Braziller, 1986. p. 27-51.

FOSTER, R. F. W. B. Yeats: A life. I: The Apprentice Mage, 1865-1914. Oxford: Oxford University Press, 1998.

FOSTER, R. F. W. B. Yeats: A life. II: The Arch-Poet, 1915-1939. Oxford; New York: Oxford University Press, 2005.

GILBERT, S.; GUBAR, S. The Madwoman in the Attic: The Woman Writer and the Nineteenth-Century Literary Imagination. London: Yale University Press, 1979.

GUNN, L. Tubercular Disease of the Seminal Tract. Transactions of the Royal Academy of Medicine in Ireland, vol. XXIV, p. 162-174, 1906.

HALPERIN, D. M. Saint Foucault: Towards a gay hagiography. New York: Oxford University Press, 1995.

LYND, R. Ireland, a nation. London: Grant Richards LTD., 1919.

MOSSE, G. Nationalism and sexuality: Middle-class morality and sexual norms in modern Europe. Madison: University of Wisconsin Press, 1985.

MUTRAN, M. H. Álbum de Retratos: George Moore, Oscar Wilde e William Butler Yeats no fim do século XIX: um momento cultural. São Paulo: Humanitas, 2002.

NORDAU, M. Degeneration. New York: D. Appleton and Company, 1895. O'DONNELL, F. H. Celtic Drama in Dublin. Freeman's Journal, I, p. 6, 1899. O'FAOLAIN, S. Vive Moi!: An Autobiography. London: Hart-Davis, 1965. PERRY, R.; PERRY, L. The Silent friend. London: n.e., 1847.

ROUSSEAU, J. J. Les Confessions de J. J. Rousseau. Londres: s.e., 1782. v.1 RUPAUL. Letting it all hang out: An autobiography. New York: Hyperion, 1995. 
SCHUCHARD, R. The Last Minstrels: Yeats and the Revival of Bardic Arts. Oxford: Oxford University Press, 2008.

SHAW, F. The Celtic Twilight: Part II. Studies, 23, 90, p. 260-278, June 1934. SQUIER, S. M. Liminal Lives: Imagining the human ant the frontiers of biomedicine. Durham: Duke University Press, 2004.

YEATS, W. B. Coole Park and Ballylee. In: The Collected Poems of William Butler Yeats. New York: Macmillan, 1956, p. 96-98.

. Dramatis personae, 1896-1902: Estrangement, The Death of Synge, The Bounty of Sweden. London: The Macmillan Company, 1936a.

. Essays and introductions. New York: Collier Books, 1968.

. Explorations. New York: Collier Books, 1962.

. Introduction. In: . (Ed). The Oxford book of modern verse: 1892-1935. Oxford: Clarendon Press, 1936b, p. xxi-xxii.

. Letters on Poetry from W. B. Yeats to Dorothy Wellesley. Ed. Dorothy Wellesley. London: Oxford University Press, 1940.

. Letters to Katharine Tynan. Ed. Roger Joseph McHugh. Dublin: Clonmore and Reynolds, 1953.

. Memoirs. Ed. Denis Donoghue. London: Macmillan, 1972.

. Preface. In: Poems: 1899-1905. London: A. H. Bullen; Dublin: Maunsel \& Co., 1906, p. xi-xv.

. Reveries over Childhood and Youth. Churchtown: The Cuala Press, 1915.

. The Letters of W. B. Yeats. Ed. Alan Wade. London: Rupert HartDavis, 1954.

. The Trembling of the Veil. London: T. Werner Laurie, 1922.

. The Speckled Bird. Ed. William H. O’Donnell. Toronto: McClelland and Stewart, 1976.

. The Winding Stair: Manuscript materials. Ed. David. B. Clark. Ithaca: Cornell University Press, 1929. 
. GONNE, M. The Gonne-Yeats Letters: 1893-1938. Ed. Ana MacBride White e A. Norman Jeffares. New York: Norton, 1994.

WOOLF, V. The letters of Virginia Woolf. Ed. Nigel Nicolson e Joanne Trautmann. London: Hogarth Press, 1979. v.5

Raimundo Sousa é doutorando em Estudos Literários pela Universidade Federal de Minas Gerais (UFMG).

Adelaine Laguardia é doutora em Estudos Literários pela Universidade Federal de Minas Greais (UFMG). Professora do Programa de PósGraduação em Estudos Literários da Universidade Federal de São João del-Rei (UFSJ). 